\title{
Glaucoma de ângulo fechado como diferencial de cefaleia trigêmino-autonômica
}

\author{
Pedro Machry Pozzobon (D), Patrick Emanuell Mesquita Sousa-Santos $\left({ }^{D}\right.$, Tarcísio Nunes Alvarenga $\left({ }^{D}\right.$, \\ Camila Bonfanti Baima
}

Hospital das Clínicas da Faculdade de Medicina de Botucatu, Universidade Estadual Paulista, Botucatu, São Paulo, Brasil.

\begin{abstract}
Introdução
Apresentamos um caso clínico de uma paciente oncológica que apresentou cefaleia nova com características trigêmino-autonômicas (CTA), porém com diagnóstico final de glaucoma de ângulo fechado (GAF).

\section{Caso Clínico}

Mulher de 69 anos, com diagnóstico de adenocarcinoma de cólon metastático (fígado, pulmão e peritônio), apresentando cefaleia nova iniciada após quimioterapia, em região frontal direita, sem piora com decúbito ou Valsalva, contínua desde a instalação, associada a vômitos. Após 3 dias de sintomas, apresentou hiperemia ocular, lacrimejamento e rinorreia, procurando assistência médica no dia seguinte. Ao exame, apresentava à direita redução da acuidade visual, edema palpebral, hiperemia conjuntival e pupila com discreta midríase não reativa a luz. Sem alterações da motricidade ocular extrínseca. Fundoscopia sem papiledema. Realizada TC de crânio com contraste, sem lesões expansivas. Punção lombar com pressão de abertura normal, sem achados significantes na análise bioquímica e citopatológica. Avaliada pela oftalmologia, que evidenciou pressão intra-ocular (PIO) de $48 \mathrm{mmHg}$ e aventada a hipótese de GAF, sendo realizado tratamento com timolol, brimonidina, acetazolamida e manitol, com redução da PIO para $22 \mathrm{mmHg}$, com melhora completa dos sintomas.
\end{abstract}

\section{Discussão}

GAF é caracterizado por oclusão do ângulo da câmara ocular anterior, alterando a drenagem do humor aquoso, levando ao aumento da PIO e dano ao nervo óptico. Apresenta-se com redução da acuidade visual, dor ocular, cefaleia, vômitos, hiperemia conjuntival, pupila médio-dilatadas bradirreagentes. Trata-se de uma condição com risco de perda da visão, considerada uma emergência oftalmológica. $\mathrm{O}$ tratamento inclui agentes redutores da PIO e iridotomia.

\section{Conclusões}

GAF é um importante diagnóstico diferencial de dor ocular, especialmente em idosos. A semiologia é imprescindível no diagnóstico, com destaque para anamnese e exame pupilar, que ajuda a diferenciar de CTA. A melhora após redução de PIO fecha o diagnóstico.

Palavras-chave: Cefaleia secundária, Cefaleia trigêmino-autonômica, Glaucoma de ângulo fechado 